\title{
Special issue "International Symposium on Molecular Logic and Computational Synthetic Biology: MLCSB18"
}

\author{
Tomas Veloz ${ }^{1} \cdot$ Madalena Chaves $^{2} \cdot$ Manuel Martins $^{3}$ \\ Accepted: 6 March 2021 / Published online: 26 March 2021 \\ (c) The Author(s), under exclusive licence to Springer-Verlag GmbH Germany, part of Springer Nature 2021
}

This special issue includes seven peer-reviewed articles about synthetic biology, whose aim is to develop formal models for biological-like phenomena, specially in the context of molecular logic (Djordević and Silva 2019; Nemati and Torres 2020; Santiago et al. 2020; Braccini et al. 2020; Moreira et al. 2020; Tavares et al. 2021; Veloz and Flores 2021). Molecular logic focuses on understanding logical and operational aspects on molecules and their interactions, providing a fruitful conceptual crossover between chemistry and computation with unsuspected applications.

The symposium was promoted by the project KleeCoalgebraic Modeling and Analysis for Computational Synthetic Biology (02/SAICT/2017), a R\&D project supported by the Portuguese Foundation for Science and Technology (FCT), within project POCI-01-0145-FEDER-030947.

The special issue was developed as a complement after the successful International Symposium on Molecular Logic and Computational Synthetic Biology (MLCSB18), held in Santiago Chile in December 2018, which brought together an interdisciplinary group of speakers and attendants at the intersection between applied mathematics, biology, computer science, and philosophy. Invited lectures were given by Marta Kwiatkowska (U. Oxford, UK), Hidde de Jong (Inria, Grenoble, France) and Alexandre Madeira (U. Minho, Portugal). The MLCSB18 symposium emerged from a series of informal workshops on Molecular Logic which, since 2014, have brought together researchers from different latitudes and backgrounds. The symposium was organized by the Institute of Philosophy and Complexity Science and the Universidad Diego Portales from Chile, and the University of Aveiro from Portugal, and hosted at both Chilean institutions. The authors of the best papers presented at

Tomas Veloz

tveloz@gmail.com

1 Foundation for the Interdisciplinary Development of Science, Technology and Arts, Santiago, Chile

2 Université Côte d'Azur, Nice, France

3 University of Aveiro, Aveiro, Portugal the MLSCB where invited to submit to this Special Issue. The decisions were made based on single-blind peer review by at least two reviewers. Conflicts of interest within the editors were dealt with using conflict of interest declarations.

The aim of MLSCB18 was harnessing logical and algebraic methods for modeling and verifying systems on the interaction of Nature and Computation, around two main themes, which can also serve to split the list of articles published in this special issue: The development of biological computation models and devices (Djordević and Silva 2019; Braccini et al. 2020; Tavares et al. 2021; Veloz and Flores 2021), and the application of new computing paradigms to the design of biological systems (Nemati and Torres 2020; Santiago et al. 2020; Moreira et al. 2020).

In conclusion, the guest editors hope that this special issue will find its numerous readers and would like to express their sincere gratitude to all authors who submitted their work, to all reviewers for their time, to the Editors-in-Chief of Soft Computing, Professors Antonio Di Nola and Raffaele Cerulli, to the associate editors which strongly collaborated with us during the editorial process Ciriaco D'Ambrosio and Harini Balasubramanian, as well as the technical staff of Springer, for their valuable support.

\section{References}

Djordević J, Silva CJ (2019) A stochastic analysis of the impact of fluctuations in the environment on pre-exposure prophylaxis for HIV infection. Soft Comput. https://doi.org/10.1007/s00500-01904611-1

Nemati S, Torres DF (2020) A new spectral method based on two classes of hat functions for solving systems of fractional differential equations and an application to respiratory syncytial virus infection. Soft Comput. https://doi.org/10.1007/s00500-019-04645-5

Santiago R, Martins M, Figueredo D (2020) Introducing fuzzy reactive graphs. A simple application on Biology, Soft Computing

Braccini M, Roli A, Villani M, Serra R (2020) Dynamical properties and path dependence in a gene-network model of cell differentiation. Soft Comput. https://doi.org/10.1007/s00500-020-05354-0 
Moreira L, Madeira A, Barbosa LS (2020) A semantics and a logic for Fuzzy Arden Syntax. Soft Comput. https://doi.org/10.1007/ s00500-021-05593-9

Tavares C, Oliveira S, Fernandes V, Postnikov A, Vasilevskiy MI (2021) Quantum simulation of the ground-state Stark effect in small molecules: a case study using IBM Q. Soft Comput. https://doi. org/10.1007/s00500-020-05492-5
Veloz T, Flores D (2021) Toward endosymbiosis modeling using reaction networks. Soft Comput. https://doi.org/10.1007/s00500-02005530-2

Publisher's Note Springer Nature remains neutral with regard to jurisdictional claims in published maps and institutional affiliations. 